\title{
The value of occupational therapy intervention for the worker roles of forensic mental healthcare users in Cape Town, South Africa
}

\author{
Mogammad Shaheed Soeker*, Saabirah Hare, Saadia Mall and Jean van der Berg \\ University of the Western Cape, Bellville, Republic of South Africa
}

Received 18 June 2019

Accepted 28 November 2020

\begin{abstract}
.
BACKGROUND: There is a void in research that focuses on how OT programs facilitate self-esteem in forensic mental healthcare users' return-to-work in the open labor market, particularly in South Africa.

OBJECTIVE: To explore the experiences and perceptions of forensic mental healthcare users, transitioning from an OT program to the open labor market.

METHODS: Five individuals, diagnosed with Schizophrenia, and two key informants participated in this study that was positioned in a qualitative paradigm, with an exploratory and descriptive design. Semi-structured interviews were used to collect data.

RESULTS: Theme one reflects on the challenges experienced by forensic mental healthcare users, when returning to work. Theme two describes various OT programs, as well as how they facilitate the reintegration of forensic mental healthcare users into the worker role. Theme three describes the positive support for forensic mental healthcare users, in the mental healthcare setting, workplace, and the greater community. Theme four describes how participation in occupation installs hope in forensic mental healthcare users, reinforcing the value of work, while positively influencing their work identity. CONCLUSION: The results revealed that stigma, residual symptoms, relapse due to substance abuse/mental health, and the lack of family support, were not conducive to work skills development. However, the support of family and friends, workplace occupational therapy support, assembly line work, and therapeutic groups in an OT program, ensured positive workplace reintegration.
\end{abstract}

Keywords: Open labor market, OT program, coping skills and strategies, workplace reintegration, rehabilitation

\section{Introduction}

Government forensic psychiatric institutions in Cape Town are concerned with the treatment and rehabilitation of individuals with mental illnesses, who had been classified as forensic patients. The aim of forensic rehabilitation services is to provide care

*Address for correspondence: Mogammad Shaheed Soeker, University of the Western Cape, Robert Sobukwe Road, Bellville, 7535, Republic of South Africa. Tel.: +27 21959 9339; E-mail: msoeker@uwc.ac.za. for, and treatment to forensic mental healthcare users, who are placed at different levels of a forensic psychiatric institution, namely, low, medium, and high security [1]. In the South African context, these secure units are categorized according to gender and age, implying that males and females, as well as adolescents and adults, are separated [2]; however, individuals with different types of psychiatric diagnoses, may be placed in the same unit. Although many benefits could be derived from these services in forensic units, the structure of such facilities restricts participation in many areas of occupation [3]. Mental 
healthcare users (MHCU) in forensic psychiatric settings, may experience dual-stigmas, from being diagnosed with a mental illness, as well as being labelled a criminal, due to their criminal record, related to their mental illness, which could result in decreased self-esteem [4]. The term, dual-stigma, is also referred to as a double-stigma, which occurs when an individual experiences stigma for more than one reason. For example, an individual could be diagnosed with a mental illness, and experience stigma. Simultaneously, the individual could display homosexual tendencies, and, once again, experience stigma; consequently, experiencing dual-stigma [5].

MHCUs become forensic patients, when certain criteria dictate the necessity, including the court's finding that the accused is incapable of understanding the legal procedures, or is unfit to plead. The court, therefore, would direct that the charged individual be confined in a psychiatric hospital [6]. However, after an accused individual is directed to such a hospital, s/he could be tried and prosecuted for the offence, if $s /$ he is observed to be capable of understanding the procedures, sufficiently, to influence a legitimate defence [7]. Additionally, in the event that the court finds the accused not criminally accountable, due to the mental illness, s/he may be found not guilty, or directed to be incarcerated in a psychiatric hospital, or a specific prison [7].

Currently, there is a dearth of literature that focuses on the usefulness of occupational therapy, particularly in a forensic setting [8]. Therefore, it is essential to gain an understanding of the strategies that individuals, diagnosed with schizophrenia, employ, when adapting to work in the open labor market. It is anticipated that this information could be beneficial in the development of vocational rehabilitation programs that aim to facilitate the smooth transition of MHCUs to employment in the open labor market. The motivation for conducting this current study is elaborated upon in the following literature review.

\section{Literature review}

In the literature review, a discussion ensues on the types of mental health related conditions, the importance of work as an occupation/activity for individuals with mental health conditions, as well as the barriers related to work for MHCUs, who have become forensic patients. Finally, the discussion is focussed on occupational therapy programs, the forensic healthcare users' return to work, and statistics related to the types of mental health related conditions observed in a forensic ward.

The primary diagnosis of a study conducted at a psychiatric institution in South Africa that involved 167 randomly selected MHCUs, was schizophrenia, documented at $45.5 \%$ of the sample. The second most common diagnosis was Bipolar Mood Disorder (BPM), documented at a $19.16 \%$ occurrence, while substance-related disorders was the third most common diagnosis, at $16.7 \%$ [9]. In addition, a study conducted at Sterkfontein Hospital in South Africa, with a sample population of 114 participants, admitted during 2004 and 2005, reinforced the fact that the majority of the patients were diagnosed with Schizophrenia (44\%), while the second most common diagnosis was Psychosis (20\%), and the third most common diagnosis, mental retardation (16\%) [9]. This statistic is important, as it highlights that Schizophrenia is one of the most common diagnoses for MHCUs, placed in forensic psychiatric settings. In this current study, the majority of the research participants were diagnosed with Schizophrenia.

Additionally, research has revealed that more male than female MHCUs receive treatment in forensic units [10]. However, Cordingley warns of dynamics between male MHCUs and female therapists in psychiatric rehabilitation units, which has raised concerns about the effectiveness of rehabilitation [11]. Evidently, male participants displayed a tendency of not trusting female therapists, and often did not respond to rehabilitation, as they should, or had to. In addition, some male participants, often, would not complete the rehabilitation on time, due to their disregard for the rehabilitation program. This issue could be related to some male participants' disrespect towards female therapists, as authority figures [11]. These dynamics could negatively affect the therapeutic relationship between the male participants and the female therapists.

Work, as a meaningful occupation/activity for mental health care users, has been described as one of the major performance areas that plays a vital role in a mental health care user's life, to be able to earn money and pay expenses, in order to survive [12]. This suggests that work is an important activity that assists MHCUs to develop meaning in their lives, particularly when work provides a routine, and enables them to socialize, and access basic necessities, such as food, electricity, as well as education. However, these are not the only benefits of work.

According to King and Olson [13], work facilitates the development of an individual's competence, 
self-esteem, sense of belonging and volition. Additionally, work is imperative to the mental health and prosperity of individuals [13]. It is a focal part of life for most individuals, and offers financial security, esteemed personal roles, social identity, and a chance to make a significant contribution to the community. Suitable employment empowers social and financial participation in the community [1].

It could be argued that the current economic situation in South Africa presents significant barriers to the successful acquisition of work. However, for individuals in forensic psychiatric placements, or who suffer from a mental illness, with a criminal record, it is a greater challenge to access work [1]. MHCUs with a criminal record would be exposed to stigma in the work place, which would negatively affect their socio economic circumstances.

Forensic mental health services focus on alleviating symptoms of psychiatric disorders linked to a criminal offence [15]. The role of the OT in such a setting, is to assess and treat mentally ill offenders. In addition, the MHCUs in McQueen's [15] study envisaged that engaging in work-related activities improved their self-confidence, which created a sense of self-worth, and facilitated a sense of identity, besides being a mentally ill criminal.

The objectives of most treatment programs for forensic clients are to enable and support individuals to recover, or adjust, in order to manage their symptoms better, and achieve their potential to lead a full and active life, when reintegrated into the community. Most often, when the focus is not directed at enhancing the worker role of MHCUs, they are not being enabled to find employment in the open labor market. Therefore, any treatment program should include developing confidence, self-belief, and self-esteem, as well as encouraging appropriate communication, and building MHCU's mental capacity, for them to find employment. McQueen [15], who conducted a study on the best evidence of vocational rehabilitation in the United Kingdom, asserts that any good treatment program will focus on the above, and develop work-related skills for the purpose of work reintegration.

\subsection{Barriers that prevent individuals with mental health conditions from returning to work}

Evidently, the stigma attached to being diagnosed with a mental health condition is viewed as a barrier. One of the most significant consequences of the stigma attached to mental illness is its negative impact on the mental health care user's self-esteem [16]. The findings of a study, conducted by Moore [2], on forensic psychiatry in South Africa, revealed that increased perceptions of stigma, prior to inmates' release from prison, was a predicating factor of poor adjustment in the community, which included their functioning in the community, as well as their areas of employment. In addition, the anticipation of experiencing future stigma, contributed greatly to this poor adjustment.

People suffering from mental illnesses experience stigma in various ways, namely, publicly and internally. Public stigma is distinguished from personal stigma, as it is representative of prejudice and discrimination that is directed at a target group of the population, which could result in self-stigma, where these public attitudes are internalized. Self-stigmatization may result in negative emotional reactions, such as low self-esteem, and diminished self-worth [16].

Other barriers include relapsing and not completing rehabilitation programs, as well as poor socio economic circumstances, and the lack of education and training, to enhance work-related skills.

\subsection{Occupational therapy programs and return to work}

Moore [2] discusses the changing levels of focus, regarding OT programs in a forensic psychiatric setting. In high security-wards, for example, the focus is on the orientation and assessment of patients, where, as in an open ward, or low-security setting, the patients are given more responsibility, in preparation for community reintegration, which could include RTW. OT programs have been regarded as the most suited to enhance the work skills of MHCUs. Clients, who had been reintegrated back into community settings, have often participated in OT programs, which provide them with the necessary life skills, to adapt to their various roles in the community.

In conclusion, work greatly influences self-esteem, and the importance of work to any one individual, cannot be argued. There are multiple factors, such as the dual stigma, that affect an individual's ability to RTW, especially in the case of an individual, who is suffering from a mental illness, and has committed a crime. Ultimately, performance in the workplace may be affected because of these factors. The literature reviewed resulted from the researchers' intention to explore the effectiveness of RTW programs, from the perspective of MHCU, specifically pertaining to how 
RTW programs prepare patients, who are returning to work in the OLM.

\section{Aim}

The aim of this study was to explore the experiences and perceptions of mental healthcare users, regarding the usefulness of occupational therapy programs in a psychiatric forensic setting, on their worker roles, when returning to the open labor market.

\section{Research paradigm and research design}

This current study was positioned in the interpretive paradigm, which presumes that social reality is the effect of the subjective elucidations of people. It observes the social world as a procedure that is produced by people, as well as that social reality needs to be viewed from the perspective of an individual [17], specifically, the experiences and perceptions of MHCUs and key informants, such as occupational therapists, about the usefulness of occupational therapy programs in forensic settings, to enhance the worker roles of MHCUs.

In this current study, the researchers employed a qualitative exploratory descriptive research design. Qualitative researchers study topics in their natural settings, interpreting social phenomena, in terms of the significance people bring to them [17]. Research that is exploratory in nature could be identified as the exploration of new phenomena, in order to develop an understanding of people or events. A qualitative exploratory approach enabled the researcher to obtain detailed information on the perceptions of mental healthcare users, regarding the usefulness of occupational therapy programs in a psychiatric forensic setting.

\section{Population and sampling}

Five participants were purposively sampled from the statistical records of the Occupational Therapy departments of Psychiatric Hospitals in the Western Cape, South Africa. Purposive sampling is defined as a sampling strategy, employed to select participants, based on their specific experience, related to the objective/s of the study [18]. Purposive sampling was used as the researcher aimed to explore the specific experiences of MHCUs, who had participated in a forensic rehabilitation program, and had successfully transitioned to open labor market employment, after rehabilitation. This sampling strategy was important, as the majority of MHCUs, who had participated in forensic programs in the South African context, were dependent on a government disability grant. The MHCUs participated in vocational rehabilitation programs, which were focused on improving their work skills, for a period of 6 weeks. The inclusion and exclusion criteria of the study are presented in Appendix A.

\section{Data collection}

The researchers were qualified occupational therapists, who conducted 2 semi-structured interviews, 60 minutes in duration, with each participant, including the key informants (See Table 1). The interviews were conducted with five MHCUs and two key informants (one occupational therapist and one occupational therapy assistant) until data saturation was reached. The researchers included individuals diagnosed with mental health conditions, as well as key informants, as occupational therapists, who were knowledgeable about the occupational therapy programs in psychiatric forensic settings. It was anticipated that the information provided by both the MHCUs and

Table 1

Demographics of the participants

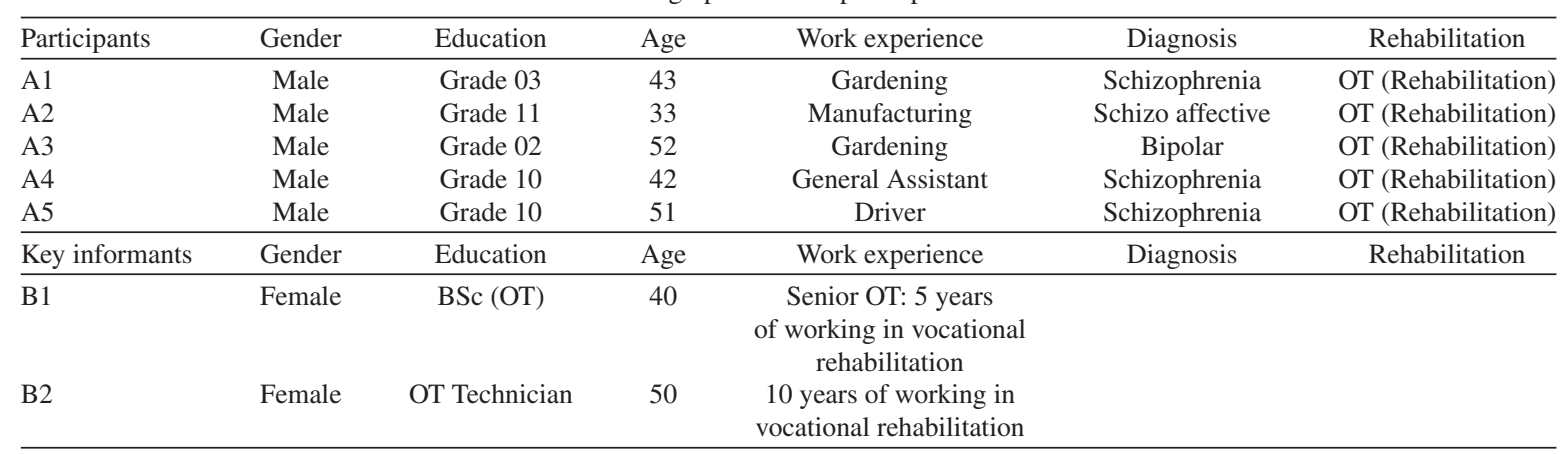


key informants would complement each other, particularly their descriptions of the usefulness of occupational therapy programs. The researchers had no prior contact with the participants, as the names of the participants were obtained from the statistical records of one psychiatric hospital that has a program for MHCUs, who are classified as forensic patients.

During the data collection phase, regarding the information reported by the research participants, the researchers did not observe any disparities that negatively highlighted problematic relationships between the male research participants and the female key informants, who were occupational therapists providing occupational therapy in forensic settings at psychiatric hospitals. The clinicians at the hospitals contacted the participants and informed them about the study. Subsequently, the participants were given the opportunity to contact the researchers themselves. After indicating their interest to participate in this current study, the prospective participants were contacted by the researchers, who proceeded to describe the aim and requirements of the study, in more detail to them. The study participants received no financial compensation for participating in the study. During the interviews, the researchers used an interview guide to steer the dialogue, which involved asking questions that were relevant to the study (See Appendix B). The data gathering took place at the Occupational Therapy Department of the Psychiatric Hospital, where the MHCUs received treatment/intervention. The researchers prepared each interviewee for the interview by building a relationship, as well as explaining the study beforehand, to ensure that the participant was relaxed and comfortable.

\section{Data analysis and trustworthiness}

The researchers used a data analysis method described by Braun and Clark [19], which suggest six steps to be followed for an effective data analysis process. Firstly, after the data collected from all the participants were transcribed verbatim, the researchers had to familiarize themselves with the data by reading all the transcripts carefully, while recording their thoughts, in writing, in the margins. Step two involved coding interesting highlights of the information on individual transcripts, in a methodical manner. In step three, these topics were grouped into columns that were identified as themes.
Step four involved inspecting the themes in connection with the coded extracts, and producing a thematic guide of the examination. Step five comprised the refining of the themes, as well as the general story linked to the themes. Finally, step six involved producing a report of the findings of the study.

The researchers used strategies such as, credibility, transferability, dependability and confirmability were used to ensure the trustworthiness of the data [20]. Credibility was ensured by the dense description of the lived experiences of the research participants. Credibility was also enhanced by triangulation, which was ensured by the use of more than one source of collecting data, for example, MHCUs and the key informants. Transferability was ensured by the detailed description of the research methods, contexts, and the lived experiences of the participants.

Dependability was ensured by means of dense descriptions, peer examination, and triangulation. The study was documented in such a manner that the readers could follow an audit trail. Field notes relating to the researcher's observations of the setting during a data collection, including notes about the context of data collection, were kept in electronic folders. Confirmability was ensured by the process of reflexivity, during which the researcher's own biases or assumptions were revealed through the maintenance of a reflexive journal.

The current study was approved by the Institutional Review Board of the University of the Western Cape, under ethics number BM/18/5/16.

\section{Findings}

In the following section the researchers discuss the findings of this current study. The data analysis revealed four themes related to the usefulness of occupational therapy programs in enhancing the work skills of MHCUs. The following themes are discussed (Table 2):

1) Theme one: Challenges that MHCUs in a forensic setting face: "It's not just the mental illness";

2) Theme two: OT programs enable reintegration to the worker role;

3) Theme three: Positive support for MHCUs in a forensic setting in RTW; and

4) Theme four: Participation in occupation instils hope for an individual. 


\subsection{Theme one: Challenges that MHCUs in a forensic setting face: "It's not just the mental illness"}

Theme one was characterized by the challenges that MHCUs in a forensic setting face, both in the workplace and at the psychiatric institution, prior to returning to work, which are explored through various categories and sub-categories.

\subsubsection{Category 1.1: Global challenges affecting the work functioning of MHCUs in a forensic setting}

This category emerged from both the key informants and MHCUs, through in-depth discussions of the challenges that MHCUs faced in a forensic setting. These challenges impact on functioning in preparation for RTW, as well as their performance in the workplace. According to one key informant, there are many challenges that MHCUs face in a forensic setting, such as which includes the effects of the mental illnesses, substance abuse, as well as the relapse of substance abuse and medication, on their ability to return to work. One key informant stated the following:

'.. Sometimes a client has just been ill for so long you know that they haven't been in ehm, you know, one hasn't been able to reintegrate them and it might be illness - pure illness or it might be poor management of medication which relates to relapse, it might be also use of substances that it has taken them out of the workplace for a very long time.' (Key Informant 3).

This category is discussed further under the subcategory, Recurring challenges faced by MHCUs in a forensic setting.

8.1.1.1. Sub category 1.1.1: Recurring challenges faced by MHCUs in a forensic setting. This sub-category emerged when the key informants extensively discussed the challenges that MHCUs often face in a forensic setting. These challenges, namely substance abuse, relapse, and residual symptoms, influence reintegration into their worker roles and could result in a complete set-back. The key informants expressed the following regarding the issue of substance abuse:

'But with substances we know that, that makes the illness worse, so it impacts on recovery, it impacts on behavior and all of those things might also influence them, when they are reintegrating.' (Key Informant 3)

One key informant also mentioned, in relation to a client of hers, how residual symptoms impacts on the MHCU's ability to form social and work relationships in the workplace. She stated the following:

'they might have residual psychotic symptoms that might impact on their ability to work at any given place' ... 'it impacts significantly on his social, social functioning within the work environment, so it limits him from forming, uhm, significant relationships or, you know, work relationships.' (Key Informant 1)

Stigma emerged from discussions with the MHCU participants, as well as the key informants, as another prominent issue that MHCUs in a forensic setting face in the workplace. The following direct quotation refers:

'... .stigma is something that's a major issue whether they've been working or not.' (Key Informant 1).

One of the participants shared his experiences with stigma in the workplace, due to his mental illness. He shared the following:

'I did tell her in the ward round already I don't wanna work there because they insult me - the manager was like "yah you, blady mal ding" (crazy person).' (Participant 4)

'... when I started working the people know me from a psychiatric hospital man, there's a "cloud" above you; there's a name tag above you... You immediately in a category, you immediately dangerous...' (Participant 4)

In addition, this participant described the impact and the side effects of medication on MHCUs in a forensic setting, as follows:

'there's lots of patients that the work they do, the way they are with the medication they like... stiff man, you know, they like zombie.' (Participant 4)

'The treatment they give is really tough, that treatment, the clozapine and all that stuff it makes you already sleepy.' (Participant 4) 
Table 2

Overview of themes and categories

\begin{tabular}{ll}
\hline Themes & Categories \\
\hline Theme 1: Challenges that MHCUs & $\begin{array}{l}\text { 1. Global challenges affecting the work functioning } \\
\text { of MHCUs in a forensic setting }\end{array}$ \\
$\begin{array}{c}\text { in a forensic setting face: "It's not } \\
\text { just the mental illness" }\end{array}$ & $\begin{array}{l}\text { 2. A lack of autonomy negatively influences the worker role } \\
\text { Theme 2: OT programs enable reintegration }\end{array}$ \\
$\begin{array}{l}\text { 1. Phased in work-related activities enhances work skill development } \\
\text { to the worker role }\end{array}$ & $\begin{array}{l}\text { 2. Therapeutic groups as a form of intervention facilitates worker role development } \\
\text { Theme 3: Positive support for MHCUs in }\end{array}$ \\
$\begin{array}{l}\text { 1. Ongoing support provided by the OT to enhance work performance in the workplace } \\
\text { a forensic setting in RTW }\end{array}$ & $\begin{array}{l}\text { 2. Ongoing support in the workplace facilitates the maintenance of the worker role } \\
\text { 3. Ongoing support from family and friends facilitates }\end{array}$ \\
the maintenance of the worker role
\end{tabular}

\subsubsection{Category 1.2: A lack of autonomy negatively influences the worker role}

This category emerged from the key informants as well as the MHCU participants, during extensive discussions regarding challenges with autonomy that MHCUs face in a forensic setting. Here, autonomy is expressed as a critical characteristic that strongly influences the worker role. This category is discussed, in terms of a lack of independent decision making, and an inflexible hospital routine that affects the worker role.

\subsubsection{Sub-category 1.2.1: A lack of independent} decision-making. This sub-category emerged from the key informants, as well as the MHCU participants during discussions, when it was established that MHCUs in a forensic setting have limited independence, and minimal decision-making capacity in such an institution. Consequently, this effect the MHCUs' role as workers in a forensic setting. The key informants mentioned the following regarding the manner in which MHCUs are deprived of autonomy in a forensic setting:

'Decision-making capacity - it almost feels like that's taken away from them...We try to promote that on one hand but on the other hand just the system itself takes away a lot of that.' (Key informant 3)

'I always try to, you know facilitate or enable skills, enable patients to do things for themselves...to not make them dependent, "cause once that happens they tend to expect that you must just do for them, and you can imagine how that impacts on their ability once they are within, you know, in their worker role.' (Key Informant 1)
8.1.2.2. Sub-category 1.2.2: An inflexible hospital routine and activities negatively affects the worker role. The sub-category emerged during discussions with the key informants, as well as MHCU participants regarding the dimensions of a psychiatric hospital, a significant one being the inflexible routine within such a setting. This dimension also has a negative impact on the worker role. The key informants stated:

'I mean lots of patients is not motivated at all to.. because they are so settled - they've got a roof over their head, they've got food everyday so a lot of them doesn't want to be, doesn't want to engage in work.' (Key Informant 2)

\subsection{Theme two: Occupational therapy programs enable reintegration to the worker role}

In theme two the different intervention types, in the OT program provided at the psychiatric hospital, are explored as categories and sub-categories. The theme is discussed in terms of work-related activities that enhance work skill development and therapeutic groups, which positively influence and enables successful reintegration into the worker role.

\subsubsection{Category 2.1: Phased in work-related activities enhances work skill development}

This category emerged during discussions with key informants and the MHCU participants regarding facilitators, who improved their skills for positive work performance. In this category are the subcategories of 'work preparation program enhances work skill development' and 'assembly line work enhances work skill development.' 
8.2.1.1. Sub-category 2.1.1: The work preparation program enhances work skill development. According to a key informant, past experiences are important aspects to note in order to plan future intervention:

'...you've got to look at past experience - where have they worked before, what types of work have they done, what do they wanna do, you've also gotta engage with them around what's realistic.' (Key Informant 3)

A participant stated that the work preparation program was a vital way of becoming more educated on the workplace:

'...to go face the situation at the, at the at the workplace. So, it (work preparation program) does give us, give you err a lot of support because things that you talk about that you that you deal with there at the workplace that we do it every day ...' (Participant 2)

\subsubsection{Category 2.2: Therapeutic groups as a form of intervention facilitate worker role development}

In this category, the manner in which therapeutic groups facilitate worker role development is emphasised. Life skills groups were highlighted as the soft skills that, most effectively, facilitated worker role development.

8.2.2.1. Sub-category 2.2.1: Life skills group enable work skill development. This sub-category entails discussions of the different types of topics that are covered in the life skills groups, especially the way in which these topics enable work skill development. These topics include coping skills, peer learning and self-esteem development. One participants expressed the following:

'Where you get advice on how to deal with the mental sickness like when you faced at the... at the... workplace...' (Participant 2)

'You see there are like, it helps so, so that you can have a problem at work but if you talk about it with your err fellow colleagues err then you, that's whereby you will get advises... Yeah in groups... so you get advises like maybe you, something that is gonna build up your strength (self-esteem development) so you can carry on without having any problems...' (Participant 2)
8.2.2.2. Sub-category 2.2.1: Role-play as a technique for RTW facilitation. A key informant stated that role-play is used to eliminate barriers, which accompany mental illness, and could affect the worker role. Role-play is also used in the OT setting to prepare patients for RTW. The following extract refers:

'We've also just got to look at... opportunities to do role play and things like that because our patients have a lot of anxiety.' (Key Informant 3).

'..or we do for example work here, therapeutic groups, so in my work prep group, for example, we'll do role play, you know, on what do we do when you have your interview, your first job interview.' (Key informant 1)

\subsection{Theme three: Positive support for MHCUs in a forensic setting for the purpose of RTW}

In theme three, the positive support is portrayed for MHCUs in a forensic setting, from individuals, who assist them to RTW. These supportive aspects positively influence MHCUs in a forensic setting to RTW. This support is discussed, in terms of the ongoing support provided by occupational therapists to MHCUs, as well as the ongoing support in the workplace. Additionally, this theme is discussed in terms of ongoing support provided through various relationships in the hospital environment, as well as from family and friends.

\subsubsection{Category 3.1: Ongoing support provided by the OT to enhance the MHCUs work performance in the workplace}

This category was developed from discussions with the MHCU participants, as well as key informants. It was determined that the OT provided support in various ways, which improved the forensic MHCUs worker role. This category is discussed in the following sub-categories, namely, constant encouragement enhances workplace motivation, and individual needs-based support.

\subsubsection{Sub-category 3.1.1: Constant encourage-} ment enhances workplace motivation. OTs provided constant encouragement, which subsequently, enhanced the participants' workplace motivation. A key informant expressed the following:

'Just saying that.. yes.. that you doing a good job.. you know what.. it does amazing things to patients.' (Key Informant 2) 
A participant also described how OTs motivated them in rehabilitation, as follows:

'OT's would always come around... "yay don't be like that man, you mos not like that, come man.", (Participant 4)

\subsubsection{Sub-category 3.1.2: Individual needs-based} support. Based on the interviews with the key informants, it was established that individual needs-based support was used, in addition to group intervention. The examples given by the key informants emphasised the extent to which OTs would support their patients to RTW. The key informant stated the following:

'And if that patient really requires you to go with him to the bank, you know, then I would also do something (support him) like that.' (Key Informant 1)

In addition, OTs are able to tend to the individual, client-centred needs of their patients. A key informant stated the following:

'...if it's really needed, I can actually on the day when you go to the interview, I can accompany you as a form of support.' (Key Informant 1)

\subsubsection{Category 3.2: Ongoing support in the workplace facilitates the maintenance of the worker role}

This category was determined from interviews with the key informants and the MHCU participants. On-site support and a supportive environment enhances the worker role. This category is discussed in the following sub-categories, namely, on-site support by the OT in workplace enhances work skills development, and, a trusting work environment facilitates growth.

\subsubsection{Subcategory 3.2.1: On-site support by the} OT in workplace enhances work skill development. During the interviews with the key informants, one of the OT's roles emerged as providing on-site support to MHCUs in a forensic setting, who have returned to work. A key informant explains on-site support, as well as the process, as follows:

'...initial support is quite a lot and sometimes it might be going with them to site, you know there's a lot of prep work and support that has to be done in the initial stages as you grade them into work and slowly grade down the support.' (Key informant 3)

The key informant also explained a limitation of on-site support, as follows:

'...practically it's hard for us to do onsite support.' (Key Informant 3).

The theme presented the participants' views of stakeholder support received when transitioning into the open labor market. This theme will be further described by the categories below.

\subsubsection{Category 3.3: Ongoing support from family and friends facilitates the maintenance of the worker role}

This category was developed from the key informants, as well as MHCU participants, during comprehensive discussions regarding ongoing support for MHCUs in a forensic setting. In this category, relationships in the hospital environment, as well as relationships with family and friends are focused on. This category is explored in the following sub-categories, namely family and friends in the community provide ongoing encouragement and guidance, and relationships in the hospital environment facilitates stability in the worker role.

8.3.3.1. Sub-category 3.3.1: Family and friends in the community provides ongoing encouragement and guidance. According to a participant, his mom provided support, guidance and encouragement, while he was working. The following extract refers:

'But my mom support me, every night when I come out of work she would ask me.. then she would tell me "No man, don't worry about him, just do your work ..........." That's the way she supported me.' (Participant 4)

Another participant stated how protective his family was of him:

'No, I don't have contact with other people, my sister doesn't want me to be in contact with other people, or friends, because otherwise I would go down the wrong path again.' (Participant 1)

\subsection{Theme four: Participation in occupation instils hope for an individual}

The final theme emerged from extensive discussions with the key informants and the MHCU 
participants, regarding the value and importance of work in an individual's life. This theme is discussed in terms of the value of work, as an occupation, as well as how engaging in work, affects an individual's worker identity. This theme further emphasizes the importance of engaging in productive occupations. One key informant expressed the following:

'Being engaged in a productive occupation is really, really important.' (Key Informant 3)

\subsubsection{Category 4.1: Work as an occupation provides purpose in an individual's life}

In this category, the value of work for an individual is described. This includes the financial value of work, as well as how the individual's participation in work could contribute to his/her well-being. The importance of work is emphasised in the following statement from one of the key informants:

'...work is one facet and an important facet of the client's rehabilitation within the hospital.' (Key Informant 3)

Another participant expressed the importance of work, to fulfil his role as the head of his household:

'No, I didn't see any difficulties for me, because I always wanted to work, hmm to support my family.' (Participant 5)

8.4.1.1. Sub category 4.1.1: Financial independence. In this sub-category, the role of work in providing the worker with a sense of financial independence is discussed. This sub-category is originated the discussions of various participants, regarding the importance of work for financial means. Two participants stated the following regarding the financial aspect of their jobs:

'I felt happy - Friday I get paid, then I can buy myself something nice to eat, and the money must be put away.' (Participant 3)

'It helped me a lot because I do myself, because I do work myself now. I don't rely to other people.' (Participant 5)

Another participant expressed being able to provide for himself, given his income:

'...can maybe buy myself cigarettes, and food, and save for clothes, shoes, etc...' (Participant 1)

Additionally, when asked about the meaning of work, a participant disclosed the following, imply- ing that the money he earned from work allowed him to be financially independent:

'Uhm, it's about not having to ask another person (for something)]...' (Participant 1)

\subsubsection{Category 4.2: Engagement in the worker role enhances one's worker identity}

This category emerged from discussions with the key informants, as well as the MHCU participants regarding how engaging in work enhanced their identity as workers. This includes capacity building in preparation for engaging in their worker role, which ultimately contributes to worker identity. A key informant stated:

'We really need to look at how to build capacity of skilling our clients you know, in order to make them more employable or to help them within their work setting itself.' (Key Informant 3)

One of the key points identified, relating to this category, is that work moulds an individual's worker identity, as illustrated in the following extract:

'...knowing that he's in a routine of getting up early in the morning. I need to have breakfast at a certain time, I need to groom myself, my personal hygiene must be, you know, to the T, because I'm now going to work.' (Key Informant 1)

8.4.2.1. Sub-category 4.2.1: A sense of meaning and contentment in life. This sub-category emerged from the participants' discussions on the effect of work on their emotional state, as well as how work contributed to their happiness, and affected their own future planning goals. This is depicted in the following statement from one of the participants:

'I can't sit and sleep whole day there...I have to get up, I have to go to work now that's the good thing of it, pushing me to go work.' (Participant 4)

The same participant also stated the following, regarding his future:

'I still want my own, so that's what I'm working for, I'm working towards my goals also - to have 2 cars, see, to have my own family, 2-3 kids, but yeah, that's what I'm also working towards...I still strive towards that, you see.' (Participant 4)

8.4.2.2. Sub-category 4.2.2: Building work-related capacity. This final sub-category relates to how 
work-related capacity is built prior to RTW, from the views of the key informants, as well as the MHCU participants. Building work-related capacity has the potential to increase the employability of patients, as expressed in the following statement:

'...we really need to look at how to build capacity of skilling our clients you know, in order to make them more employable or to help them within their work setting itself.' (Key Informant 3)

A participant disclosed being prepared for engagement in the worker roles, as per the following extract:

'Yeah, it, it makes you prepared I can say. It makes you confident so that when you are at the workplace you don't feel like err you are doing something that you so like it's your first time. It's like doing something you already prepared to do, it's like yeah, something that you prepared to, to do.' (Participant 2)

\section{Discussion}

\subsection{Barriers}

MHCUs in a forensic setting experience multiple challenges when returning to work.

\subsubsection{Global challenges affecting the work functioning of MHCUs in a forensic setting}

These challenges ultimately contributed to a decrease in work performance, consequently hindering successful rehabilitation and re-integration to the workplace. One of the key informants discussed the multiple challenges that participants face, including the length of time spent in rehabilitation and outside of work, the severity of the mental illness, poor management of medication, the issue of relapse, as well as the issue of substance abuse. The key informant indicated that all these challenges could increase the time spent in the hospital environment, which therefore, hinders RTW. According to Elsayed et al. [21], there is a well-known relationship between substance abuse and crime. Of the 100 participants involved in the aforementioned study, $56 \%$ were observed to have been abusing substances, which correlates with studies that identify mentally ill offenders, suffering from a dual diagnosis, as a high-risk group for committing crimes. In support of this literature, substance abuse was identified by the key informants as a major aspect that could exacerbate the effects of the mental illness, and therefore, impact on recovery, behavior, and reintegration into the workplace.

Lam et al. [22] discussed the importance of relapse prevention of individuals with schizophrenia, as each relapse increases residual symptoms, which could lead to a gradual decrease in functioning, as well as a disruption in an individual's life. In addition, despite antipsychotic medications to reduce psychotic symptoms, many patients, suffering from psychosis, continue to experience residual symptoms, a decrease in functioning, and a high risk of relapse. According to Tregweth et al. [4], patients in a forensic psychiatric setting may experience dual-stigma, because of having a mental illness, and a criminal record. The effects of dual-stigma could result in the decreased self-esteem of MHCUs in a forensic setting, and in turn, affect their worker role. Poremski et al. [23] explain how stigma and discrimination of persons with a mental illness is a regular occurrence that expands into employment. In support of this, one of the key informants in this current study mentioned how stigma was a major issue, whether patients had been working or not.

Additionally, as discussed in this current study, the lack of support from families could result in defaulting on medication, and subsequently, relapsing. The key informants discussed how the social stressor of having, either very little, or no support, could impact on an individual's functioning. One of the participants expressed how the fault lies with the family, which emphasises the enormity of the issue of the lack of family support. Another participant also shared how fellow patients' families did not visit them, and how they remained in hospital for long periods without support from family.

\subsubsection{A lack of autonomy}

The key informants in this current study emphasised the patients' lack of autonomy, as well as how the hospital system deprives them of their independent decision-making and right to autonomy. One of the key informants shared how the decision-making capacity of the MHCUs in a forensic setting are denied by the system, despite the occupational therapists attempts to promote this, in some measure. According to Moore [2], an underlying aim of occupational therapy intervention should be to diminish institutionalisation, in order to ensure successful reintegration into the community. In support of this, a key informant shared how occupational therapists attempt 
to empower patients with skills, and be independent of others. In addition, the key informant explained that, once patients become dependent, they expect things to be done for them, which impacts on their worker role, as subsequently, they may be unable to voice their opinions, express concerns, or even be taken advantage of in the workplace. According to Chow et al. [24] the patients' right to autonomy is restricted in psychiatric institutions, merely for the purpose of maintaining their well-being. These authors further argue that, despite the presence of institutional care, which limits the patient's autonomy, a considerable amount of care is provided to patients in such settings.

\subsection{Enablers}

Despite the several challenges regarding RTW that MHCUs in a forensic setting face, the key informants and the MHCU participants identified enablers of the worker role. Phased in work programs (work preparation, and vocational rehabilitation programs), as well as therapeutic interventions (life skill groups, role-playing, and positive reinforcements), were identified as leading enablers of the worker role.

\subsubsection{Phased in work-related activities}

Both key informants and the MHCU participants highlighted the positive influences that phased in work-related activities had on work skill development, which subsequently, leads to the development of the worker role. The phased in work-related activities, at a typical psychiatric hospital, included the work preparation program, and assembly line work. A key informant discussed the importance of taking the client's past work experiences into account, when planning rehabilitation. This key informant stated that the client's past work experience guides the therapist to plan an intervention that is realistic, but simultaneously considers the clients' work goals. Opportunities for pre-employment and work-skill development should be based on individual preference [2]. In addition, Corrigan et al. [25] clarifies that work fulfils a significant role in the recuperation and rehabilitation goal-setting of individuals with mental illness. According to McQueen [15], a forensic mental health treatment program should focus on enabling and supporting individuals to recover, or adjust, in order to manage their symptoms better, as well as achieve their potential to lead full and active lives, when discharged into the community.

\subsubsection{Therapeutic groups as a form of intervention}

In addition to the work preparation and assembly line activities that participants engaged in, they also engaged in group therapy, which facilitated the development of the worker role. These groups specifically focused on life skills and role-playing work-related scenarios. The key informants, as well as the MHCU participants stated that these groups played a significant role in facilitating the development of the worker role. McQueen [15] states that a treatment program should facilitate the aim to work, by developing confidence, self-belief, self-esteem, and encouraging appropriate communication, as well as interactional skills, while building the patient's mental capacity. A key informant confirmed that punctuality, confidence, communication, money management, coping skills and community reintegration, are facilitated during life skills groups.

\subsection{Ongoing support in the workplace}

The key informants and MHCU participants in this current study indicated that the occupational therapists provided onsite support to the participants in the workplace. The occupational therapist visited the participants' workplaces (especially in the initial stages), where most support and grading of work skills occurred.

According to McKay et al. [26], the Clubhouse model of psychosocial rehabilitation has been in existence for many decades. Clubhouses are purposefully created, therapeutic, and integrated working communities for young adults, as well as adults, living with a mental illness. Additionally, this model retains the belief that work, and work-mediated relationships are recuperative [26]. The Clubhouse model creates and maintains a relationship with employers, providing on-site training and support; however, support is provided both on- and off-site, upon request from members.

\subsection{Self-esteem and work-related skills}

A key informant defined self-esteem as related to who the individual is, what s/he values, as well as what provides him/her with feelings of self-worth. Self-esteem is a vital component of an individual's life. The key informants within this psychiatric institution emphasised the importance of building an individual's self-esteem, in relation to work and the worker role. In a study, conducted by Soeker [27], that 
was focused on enhancing the work skills of individuals, who had sustained a traumatic brain injuries, it was argued that self-esteem and self-efficacy beliefs are important for the resumption of the individuals' work roles.

\subsection{Strategies that enhance occupational therapy programs}

The final objective relates to strategies that could be utilised to enhance current occupational therapy programs. The key informants, as well as the MHCU participants, provided a critique of occupational therapy programs at psychiatric institutions. These recommendations were aimed at improving the current occupational therapy programs in the hospital environment. One of the key informants recommended that, due to the low motivation levels of patients, more emphasis should be placed on motivating patients in the occupational therapy program. According to Coetzee et al. [28], screening for work readiness should be incorporated into all occupational therapy programs, which will provide a platform, from which to refer MHCUs to the Department of Labor, for future work placement and support.

\section{Limitations of the study}

One limitation of the study was the fact that mainly male participants were involved in this current study, as the researchers, unsuccessfully endeavoured to recruit female participants for the study. However, statistically, more male, than female patients, receive treatment in forensic units of psychiatric hospitals. Due to the stigma attached to individuals living with psychiatric conditions, especially those, who had committed a crime, it was a challenge to recruit additional participants for this current study. Many of the participants could only meet at the psychiatric hospital for the interviews, which may have affected their ability to provide detailed information.

The researchers could not conduct a focus group discussion, due to the availability of the research participants; therefore, only individual semi-structured interviews could be conducted. Finally, it should be stated that the male research participants did not protest that their ability to return to work were negatively affected by treatment from female occupational therapists in forensic units at psychiatric hospitals.

\section{Conclusion}

In conclusion, the key informants, as well as the MHCU participants highlighted that the barriers of stigma, residual symptoms, relapse due to substance abuse and mental health, as well as the lack of family support, was not to be conducive to work skill development. Additionally, the study participants were of the opinion that support of family and friends, occupational therapy support at the workplace, phased-in and assembly line work, as well as therapeutic groups in the occupational therapy program, were critical enablers of positive workplace reintegration for MHCUs. In addition, it was revealed that occupational therapy programs should focus on enhancing the self-esteem and self-confidence of MHCUs, which is crucial to their worker role. They further stated that, being able to work ensured a way of achieving their personal goals. Finally, the study participants indicated a strong need for occupational therapy programs to be client-centred, and incorporate job finding skills that matches the MHCUs' level of functioning.

\section{Conflict of interest}

None to report.

\section{References}

[1] Sampsona S, Edworthy R, Vollm B, Bulten E. Long-Term Forensic Mental Health Services: An Exploratory Comparison of 18 European Countries. International Journal of Forensic Mental Health. 2016, [Available online: https://www.researchgate.net/deref/http $\% 3 \mathrm{~A} \% 2 \mathrm{~F} \% 2 \mathrm{Fdx}$. doi.org\%2F10.1080\%2F14999013.2016.1221484]

[2] Moore M. Forensic Psychiatry and Occupational Therapy. In: Crouch R, Alers V, editors. Occupational Therapy in Psychiatry and Mental Health. Chichester, West Sussex, England, United Kingdom: John Wiley \& Sons, Ltd; 2014. pp. 106-114.

[3] Tiwana R, McDonald S, Vollm B. Policies on sexual expression in forensic psychiatric settings in different Euro-pean countries. International Journal of Mental Health Systems. 2016;10:5. [Available online: doi: 10.1186/s13033-0160037-y]

[4] Tregweth J, Walton JA, Reed K. The experiences of people who re-enter the workforce following discharge from a forensic hospital. Journal of Vocational Rehabilitation. 2012;37:49-62.

[5] Marshall LA, Adams EA. Building from the ground up: exploring forensic mental health staff's relationships with patients. The Journal of Forensic Psychiatry and Psychology. 2018;29(5) [Available online: https://doi.org/ 10.1080/14789949.2018.1508486] 
[6] Edworthy R, Sampson S, Vollm, B. Inpatient forensic psychiatric care: legal frameworks and service provision in three European countries. International Journal of Law and Psychiatry. 2016;47:18-27 [Available online: doi:10.1016/j.ijlp.2016.02.027]

[7] Ozkan E, Belhan S, Yaran M, Zarif M. Occupational Therapy in forensic settings. London, England, United Kingdom: Intech publishers; 2019. [Available online: https://doi.org/10.5772/intechopen.79366]

[8] Perkes D, Whiteford G, Charlesworth G, Weekes G, Jones K, Brindle S, Hoare L, Todd E, Ray M. Occupation-focussed practice in justice health and forensic mental health: Using a practice-based enquiry approach. World Federation of Occupational Therapists Bulletin. 2015;71(2) [Available online: https://doi.org/10.1080/14473828.2015.1103464]

[9] Waumsley SJ. Mental distress in context: Gender, race and diagnosis at Valkenberg Hospital. University of Cape Town. Unpublished honours research project: 2007.

[10] Adams J, Thomas SDM, Mackinnon T, Eggleton D. The risks, needs and stages of recovery of a complete forensic patient cohort in an Australian state. BMC Psychiatry. 2018;18:35. https://doi.org/10.1186/s12888-017-1584-

[11] Cordingley K. How do occupational therapists practising in forensic mental health know? A practice epistemology perspective. Unpublished Masters Thesis, Brunel University, London. 2015.

[12] Marais BS, Subramaney U. Forensic state patients at Sterkfontein Psychiatric Hospital: A 3-year follow-up study. South African Journal of Psychiatry. 2015;21(3):86-91.

[13] King PM, Olson DL. Work: In Schell BA, Gillen G, Scaffa ME, editors. Willard and Spackman's Occupational Therapy. Philadelphia, PA., USA: Lippincott Williams \& Wilkins; 2014. pp. 678-696.

[14] Waghorn G, Lloyd C. Employment and people with mental illness. Vocational Rehabilitation and Mental Health. 2010;17(29):1-18.

[15] McQueen, J. Towards work in forensic mental health: National guide for allied health professionals 2016. Available from: www.gla.ac.uk

[16] Vass V, Sitko K, West S, Bentall RP. How stigma gets under the skin: the role of stigma, self-stigma and selfesteem in subjective recovery from psychosis. Psychosis. 2017;9(3):235-44. https://doi.org/10.1080/17522439.2017. 1300184
[17] Ardalan K. Ideology: A multiple paradigmatic approach. Journal of Interdisciplinary Economics. 2018;31(2):124-42.

[18] Palinkas LA, Horwitz SM, Green CA, Wisdom JP, Duan N, Hoagwood K. Purposeful Sampling for Qualitative Data Collection and Analysis in Mixed Method Implementation Research. Administration and Policy in Mental Health. 2015;42(5):533-44. https://doi.org/10.1007/ s10488-013-0528-y.

[19] Braun V, Clarke V. Using thematic analysis in psychology. Qualitative Research in Psychology. 2006;3(77):77-101.

[20] Krefting L. Rigour in qualitative research: The assessment of trustworthiness. American Journal of Occupational Therapy. 1991;45(3):214-22.

[21] Elsayed YA, Al-Zahrani M, Rashad MM. Characteristics of mentally ill offenders from 100 psychiatric court reports. Annals of General Psychiatry. 2010;9(4). https://doi.org/10.1186/1744-859X-9-4

[22] Lam AH, Chien WT. The effectiveness of mindfulnessbased intervention for people with schizophrenia: a systematic review. Neuropsychiatry. 2016;6(5):208-222.

[23] Poremski D, Chong SA, Subramania, M. Helping People with Mental Illness Return to Employment: Challenging Existing Beliefs. Employment of People with Mental Illness. 2015;44(9):315-6.

[24] Chow WS, Priebe S. Understanding psychiatric institutionalization: a conceptual review. BMC Psychiatry. 2013;13(169):1-14.

[25] Corrigan PW, Rao D. On the Self-Stigma of Mental Illness: Stages, Disclosure, and Strategies for Change. The Canadian Journal of Psychiatry. 2012;57(8):464-9.

[26] McKay C, Nugent KL, Johnsen M, Eaton WW, Lidz CW. A Systematic Review of Evidence for the Clubhouse Model of Psychosocial Rehabilitation. ADM Policy Mental Health. 2016;45(1):28-47.

[27] Soeker MS. The experiences of occupational therapists, regarding the use of the Model of Occupational Self Efficacy as a model for returning brain injured individuals to work. Work. 2016;55(3):689-701.

[28] Coetzee Z, Goliath C, Van der Westhuizen R, Van Niekerk L. Reconceptualising vocational rehabilitation services towards an inter-sectoral model. South African Journal of Occupational Therapy. 2011;41(2):32-7. 


\section{Appendix A: Inclusion and exclusion criteria}

\section{Participants}

Below is the inclusion criteria that was used for this study:

- Participants must be between the ages of 18 and 55 years of age.

- Participants must communicate in English/Afrikaans.

- Participants must have been diagnosed and treated for a psychiatric condition according to the DSM5 in the last five years.

- Participants must have been employed in the OLM market for at least two to four months.

- Participants must have been employed in the OLM before participating in the OT program in a forensic setting.

Below is the exclusion criteria that was used for this study:

- Participants must currently not experience active phase/psychotic symptoms.

- Participants must not include clients that are currently under observation to confirm psychiatric diagnosis within the forensic ward.

Participants must not be diagnosed with multiple disabilities.

\section{Key informants}

The key informants were three OT's who had at least six months experience of working with clients in an OT program within the forensic ward in forensic psychiatric services.

\section{Appendix B: Interview guide (semi-structured) - Participants}

1. What are the barriers you faced when returning to work after you participated in an OT program at the psychiatric hospital?

Probes: What are the challenges you faced?

How did the OT program help you in overcoming the barriers?

2. What were the things or factors that helped you when returning to work after you participated in an OT program at the psychiatric hospital?
Probes:

What were the recommendations that were made by the OT program to ensure success in your job?

What about the OT program made your job easier for you?

What in the OT program helped improve your selfesteem?

What aspects in your job help you adapt to your worker role?

What aspects in your community helped you adapt to your worker role?

3. How do you view yourself as a worker after you attended the OT program?

Probes:

How has the OT program allowed you to feel better about yourself?

4. How did taking part in the OT program affect your role as a worker? Probes:

How has the OT program helped you in the workplace?

What in the program helped you improve your role as a worker?

How did the OT program prepare you for return to work?

5. How did taking part in the OT program affect your self-esteem? Probes:

What did the OT in the program do to improve your self-esteem?

How do you think the OT program could have helped you feel better about yourself? (Improve selfesteem)

6. What suggestions do you have in order to improve occupational therapy rehabilitation programs?

Probes:

What tasks or activities of the occupational therapy program could be changed?

\section{Key informant interview guide (semi-structured)}

1. What are the main barriers mental health care user face when returning to work after participating in a forensic OT program? Probe: What are some of the most common difficulties that mental health care users face when returning to work?

2. What are the barriers within the institution/ hospital that prevents the adequate preparation of mental health care for returning to work? Probe: What are the challenges, which are outside of your control, that affect OT intervention? Can 
you identify the challenges that mental health care users face in preparation for returning to work?

3. What type of OT intervention are conducted with mental health care users in preparation for going back to work? Probe: Is it individual or group treatment? What skills are taught within treatment? Can you describe how the program focuses on enhancing self-esteem in the users of the program?

4. How does OT intervention assist mental health care users in their workplace? Probe: Are there any success stories of patients returning back to work?
Probe: What skills learned in OT can be used within the workplace?

5. Are there any other ways in which OT intervention can be more effective in preparing mental health care users for a successful reintegration into their worker role? Probe: Should there be more focus placed on work rehabilitation and supportive employment in a psychiatric hospital? Probe: Describe how returning to work is a focus for OT intervention in psychiatric hospitals? 